\title{
Calcified Cerebellar Ganglioglioma in an Adult Patient: Case Report
}

\section{Erişkinde Kalsifiye Serebellar Gangliogliom: Olgu Sunumu}

\author{
Necati Tatarlı ${ }^{1}$, Özgür Şenol ${ }^{1}$, Selçuk Özdoğan ${ }^{1}$, Mehmet Tiryaki ${ }^{1}$, Yusuf Emrah Gergin ${ }^{1}$, Dilek Yavuzer ${ }^{2}$, \\ Bilgehan Solmaz ${ }^{3}$, Tufan Hiçdönmez ${ }^{1}$ \\ ${ }^{1}$ Dr. Lütfi Kırdar Kartal Eğitim ve Araştırma Hastanesi, Nöroşirürji Kliniği, İstanbul \\ ${ }^{2}$ Dr. Lütfi Kırdar Kartal Eğitim ve Araştırma Hastanesi, Patoloji Kliniği, İstanbul \\ ${ }^{3}$ İstanbul Eğitim e Araştırma Hastanesi, Nöroşirürji Kliniği, İstanbul
}

Dergiye Ulaşma Tarihi:01.03.2015 Dergiye Kabul Tarihi:20.11.2015 Doi: 10.5505/aot.2016.92485

\section{ÖZET}

Gangliogliom, genellikle çocuklarda gözlenmekte olup, sinir sisteminin nadir tümörüdür. Hem nöronal hem de glial hücrelerden oluşan mikst tipte kitledir. Erişkin yaşta oldukça nadirdir. Sıklıkla supratentorial olarak yerleşim gösteren bu tümör, çok daha az sıklıkta serebellar olarak yerleșim gösterir. Genellikle kistik olan bu lezyon, oldukça az sıklıkta kalsifiye olarak izlenir. Başağrısı ve yürüme güçlügü nedeniyle başvuran kırkaltı yaşındaki bayan olguda kalsifiye serebellar gangliogliom tespit edildi. Amacımız, erişkin yaşta görülen kalsifiye serebellar gangliogliom olgusunu sunarak, bu çok ender olarak rastlanan tümör lokalizasyonunu literatüre kazandırmaktır.

Anahtar Kelimeler: gangliogliom; kalsifiye gangliogliom; serebellar

\section{ABSTRACT}

Ganglioglioma, is commonly seen in children, is the rare tumor of the nervous system. This tumor is composed of a mixed type of neuronal as well as glial cells. It is very rare in adults. This tumor is often supratentorial showing the layout, much less often show as cerebellar location. This lesion, which is generally quite less frequently, showed as cystic and calcified tumors. Calcified cerebellar ganglioglioma was detected in forty-six-year-old female patient with headache and gait disturbance. Our goal is to present that calcified cerebellar ganglioglioma seen in adult patients, is to make the tumor localization rarely encountered.

Keywords: ganglioglioma; calcified ganglioglioma; cerebellar

\section{Giriş:}

Gangliogliom sinir sisteminin nadir görülen tümörlerinden olup, genellikle çocuklarda görülür $(1,2,3,4)$. Daha siklıkla supratentorial yerleşim gösteren bu kitle, nadiren serebellar lokalizasyonda bulunur $(5,6,7)$. Literatürde erişkin yaşta bildirilen serebellar gangliogliom olguları çok az sayıdadır (7). Amacımız, çok nadir görülen böyle bir olguyu sunarak literatüre katkıda bulunmaktır.

\section{Vaka Sunumu:}

Kırkaltı yaşında bayan olgu, iki aydır başağrısı ve yürümede dengesizlik șikayetleri ile başvurdu. Olgunun fizik muayenesi ve biyokimyasal tetkikleri normal olarak bulundu. Nörolojik muayanesinde ataksik yürüyüş dışında patoloji tespit edilmedi. Kranial manyetik rezonans görüntülemesinde (MRG) serebellar orta hatta, yer yer yoğun kalsifikasyon alanları içeren, heterojen kontrast tutan ve hafif çevresel ödemi de bulunan kitle lezyonu tespit edildi (Resim 1, 2, 3 ve 4). Olgu ameliyat edilerek, kitle total olarak çıkartıldı. Olgunun yapılan patolojik incelemesinde, glial hücrelerden ve ganglion hücrelerinden oluşan, yer yer yoğun kalsifikasyon alanları gösteren neoplastik 


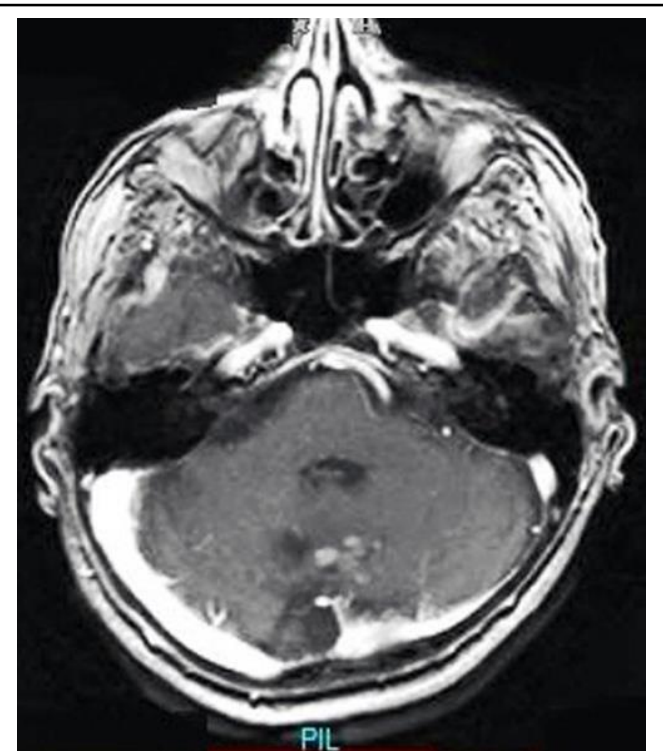

Resim 1: Kranial T1 ağırlıklı kontrastlı sagittal MRG kesitinde serebellar, heterojen kontrast tutan kitle lezyonu görülmekte (MRG: Manyetik rezonans görüntüleme).

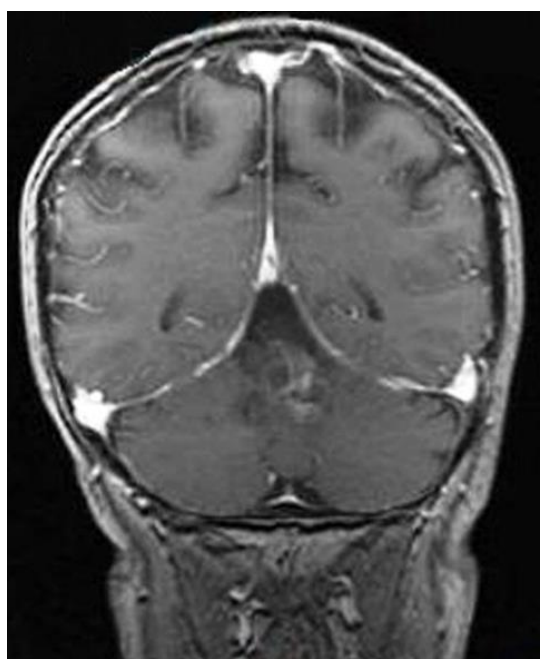

Resim 3: Kranial T1 ağırlıklı kontrastlı koronal MRG kesitinde orta hatta, serebellar, heterojen kontrast tutulumu gösteren kitle lezyonu tespit edilmekte.

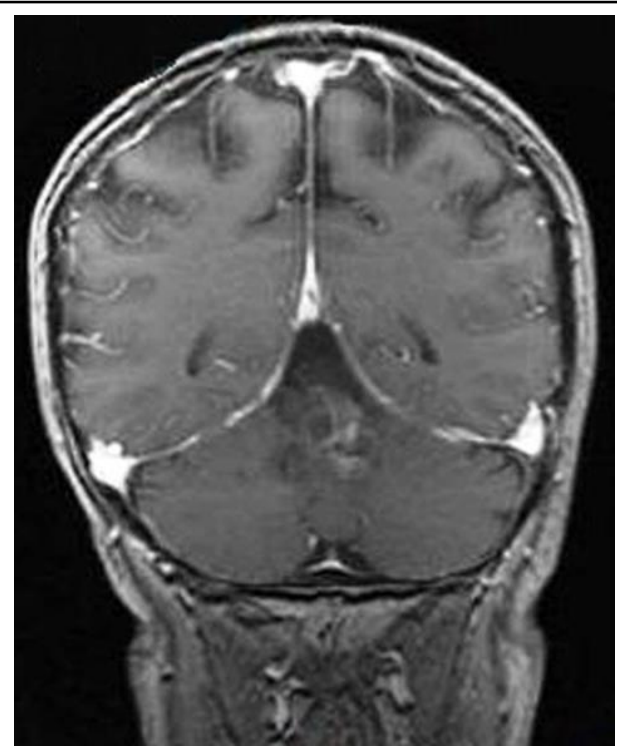

Resim 2: Kranial T1 ağırlıklı kontrastlı aksial MRG kesitinde serebellar orta hatta, yer yer kalsifiye, heterojen kontrast tutan kitle lezyonu izlenmekte.

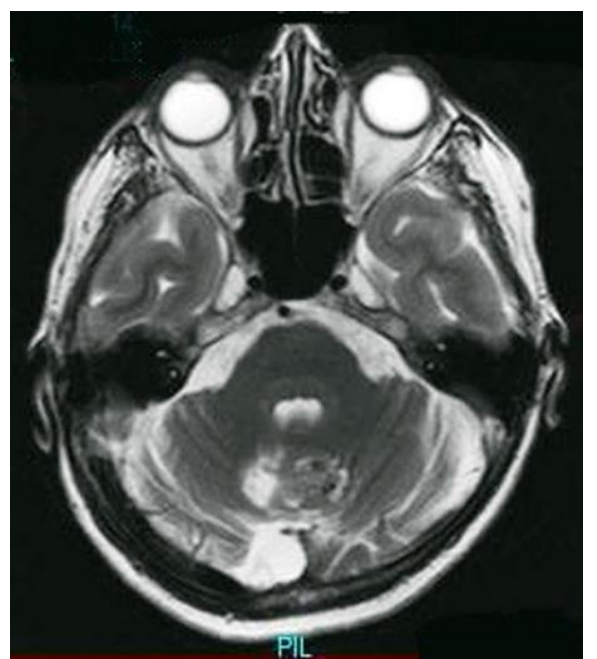

Resim 4: Kranial T2 ağırlıklı aksial MRG kesitinde serebellar orta hatta, yer yer yoğun kalsifikasyon alanları da içeren, hafif çevresel ödemi bulunan kitle lezyonu saptanmakta. proliferasyon izlendi. Glial hücreler GFAP ile; ganglion hücreleri ise sinaptofizin ve kromogranin A ile pozitif olarak boyand. Olgu, kalsifiye gangliogliom olarak rapor edildi (Resim 5, 6, 7 ve 8). Ameliyat esnasinda ve sonrasinda herhangi bir komplikasyon gelişmedi.

\section{Tartışma:}

Gangliogliom, çocukluk çağı beyin tümörlerinin $\%$ 2.5-3'ünü oluşturur. Çoğunlukla çocuklarda ve supratentorial olarak gözlenir $(1,2,3,4)$. En sik olarak temporal lobu tutar $(3,4,5)$. Ayn1 zamanda beyin sap1, spinal kord, anterior vizüel sistem, ventrikül ve serebellumdan da kaynaklanabilir. Hem nöronal kökenli ganglion hücrelerini hem de glial hücreleri beraber içeren mikst tipte tümördür. Klinik yavaş seyirli olup, supratentorial olgularda epilepsi en sik başlangıç bulgusudur $(1,3,4,8,9)$. Nöbet sıklığı, \%75-100 olarak bildirilmiștir. Serebellar nöbetler; klinikte otonomik disfonksiyon bulguları, aynı tarafta üst ekstremitede anormal hareketler, alt fasial ve göz çevresindeki 
kaslarda tek tarafta tonik/klonik nöbetler, tonik göz ve baş hareketleri şeklinde ortaya çıkabilir ve kromogranin A ile boyanırlar $(7,10,12,13,14)$. Histopatolojik olarak garip şekilli, çift nükleuslu nöronları görmek, tanı

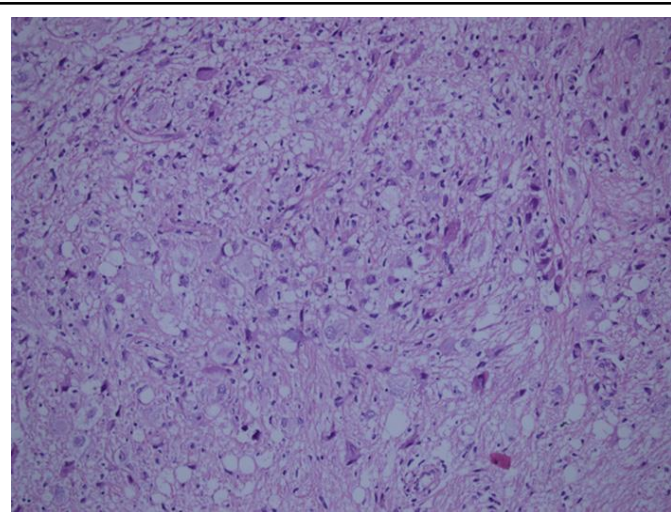

Resim 5: Neoplastik ganglion hücreleri ile glial hücrelerden oluşan tümor dokusu izlenmekte (HEx400) (HE: Hematoksilen eozin).

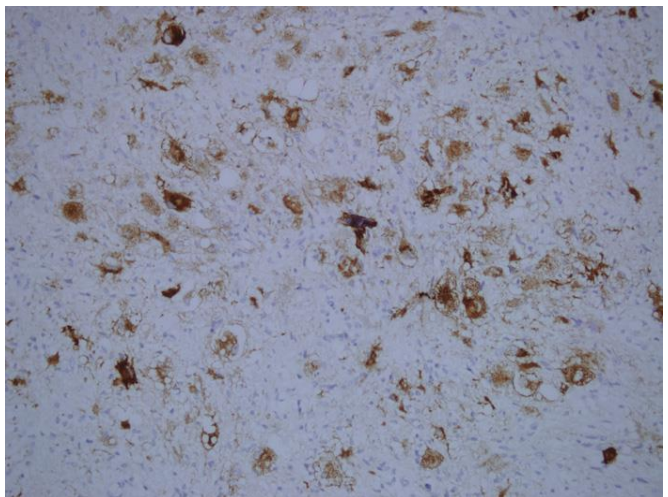

Resim 7: Kromogranin A ile ganglion hücrelerinde pozitif boyanma saptanmakta (x200).

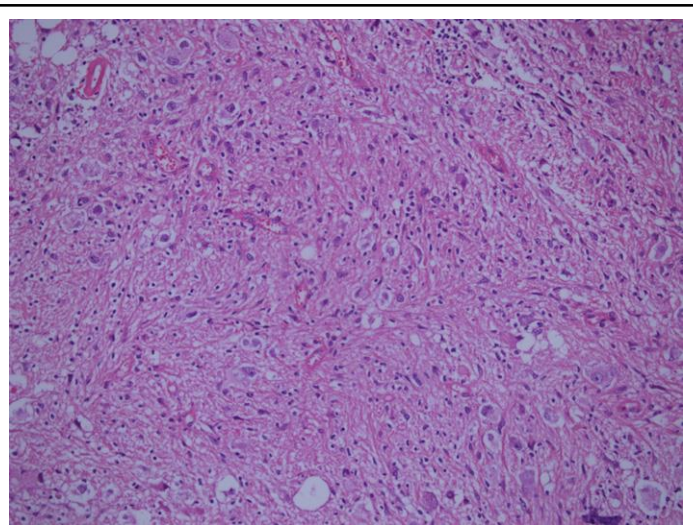

Resim 6: Neoplastik ganglion hücreleri ile glial hücrelerden oluşan tümor dokusu görülmekte (HEx200).

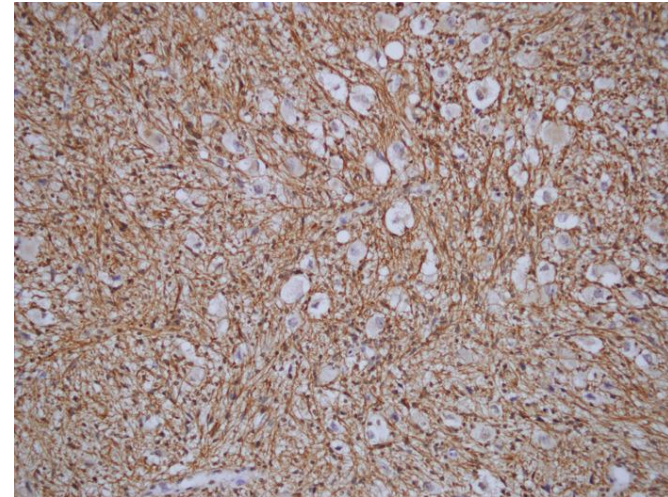

Resim 8: GFAP ile glial hücrelerde pozitif boyanma tespit edilmekte (x200).

koymaya yardımcıdır. Patolojik kesitlerde ve radyolojik görüntülerde, çevre dokudan iyi sinırlı olarak ayrılabilen kitleler olarak görülür. Malign transformasyon çok nadirdir. Malign transformasyondan sorumlu hücreler ise, glial hücrelerdir.

Gundamaneni ve arkadaşlarına göre; korpus kallosum agenezisi, Down Sendromu, polimikrogiri veya Turcot sendromu gibi konjenital anomaliler \%5 olguda birlikte bulunur (1).

Gangliogliom olgularında tedavi, cerrahidir (15). Tam rezeksiyon yapılmalidır. Tam rezeksiyon, lezyon sınırlı olduğu ve çevre dokudan ayırdedilebildiği için, genellikle mümkündür. Tam rezeksiyon ile 5 y1llık sağkalım \%90'ın üzerindedir. 
Radyoterapi, bu olgularda tartışmalıdır. Tam olarak çıkarılan lezyonda radyoterapinin yeri yoktur. Fakat, ameliyat sonras1 rezidüsü olan veya daha sonra olgunun takibinde nüks gelişenlerde; anaplastik olan tümörlerde ya da beyin sapı olgularında cerrahi sonras1 radyoterapi uygulanmalidir.

\section{Referanslar:}

1. Gundamaneni SK, Ganesh CV, Mahadevan A, Madhugiri VS, Sasidharan GM, Kumar VR. Noninfantile desmoplastic cerebellar ganglioglioma in a patient with multiple congenital anomalies: a rare association. Pediatr Neurosurg. 2013;49(2):105-9.

2. Probst A, Ulrich J, Zdrojewski B, Hirt HR. Cerebellar ganglioglioma in a child. J Neuropathol Exp Neurol. 1979;38(1):57-71.

3. Fedoul B, Souirti Z. Cerebellar ganglioglioma. Pan Afr Med J. 2012;12:12.

4. Turgut M, Ozcan OE. Cerebellar ganglioglioma. Case report. J Neurosurg Sci. 1990;34(2):151-3.

5. Mørk SJ, Berg-Jensen M, Haugen A. Cerebellar ganglioglioma. Case report. J Neurosurg. 1979;51(4):562-4.

6. Löbel U, Ellison DW, Shulkin BL, Patay Z. Infiltrative cerebellar ganglioglioma: conventional and advanced MRI, proton MR spectroscopic, and FDG PET findings in an 18-month-old child. Clin Radiol. 2011;66(2):194201.

7. Handa H, Yamagami T, Furuta M. An adult patient with cerebellar ganglioglioma. J Neurooncol. 1994;18(3):183-9.

8. Chae JH, Kim SK, Wang KC, Kim KJ, Hwang YS, Cho BK. Hemifacial seizure of cerebellar ganglioglioma origin: seizure control by tumor resection. Epilepsia. 2001;42(9):1204-7.

9. Harvey AS, Jayakar P, Duchowny M, et al. Hemifacial seizures and cerebellar ganglioglioma: an epilepsy syndrome of infancy with seizures of cerebellar origin. Ann Neurol. 1996;40(1):91-8.

10. Park SH, Kim E, Son EI. Cerebellar ganglioglioma. J Korean Neurosurg Soc. 2008;43(3):165-8.

11. Tokunaga $\mathrm{H}$, Sunami $\mathrm{K}$, Wagai $\mathrm{N}$, et al. Ganglioglioma originating in the cerebellum with a large cyst--a case report and review of the literature. Clin Neuropathol. 2008;27(6):369-72.

12. Mizuno J, Nishio S, Barrow DL, Davis PC, Tindall GT. Ganglioglioma of the cerebellum: case report. Neurosurgery. 1987;21(4):584-8.

13. Jay V, Greenberg M. Unusual cerebellar ganglioglioma with marked cytologic atypia. Pediatr Pathol Lab Med. 1997;17(1):105-14.

14. Harding M, Brophy B, Geake T. Malignant cerebellar ganglioglioma. J Clin Neurosci. 2008;15(5):582-5.

15. Nishizawa S, Yokoyama T, Ryu H, et al. Cerebellar ganglioglioma--case report. Neurol Med Chir (Tokyo). 1991;31(12):777-81.
Literatürde erişkinde kalsifiye serebellar gangliogliom olgularına nadir olarak rastlanmaktadır. Bu olgu dolayısıyla erişkinde görülen serebellar kalsifiye kitlelerde, serebellar gangligliomu da akılda tutmak gerektiği vurgulanmak istendi. 